\title{
artículos
}

\section{In Nomine Satanás: la imagen del diablo en el rock del los años 80}

\author{
Alexis Navas Fernández \\ Investigador vinculado a la UMA
}

\section{RESUMEN}

Este trabajo estudia la identificación de las bandas de rock con la iconografía de carácter satánico. Reconociendo en el ángel caído la personificación de la rebeldía contra los sistemas establecidos y lo políticamente correcto, el tema tiene también su oportuno reflejo en las letras de los temas, en los soportes publicitarios y, con bastante frecuencia, también en el "modus vivendi" de los practicantes y adeptos del "metal".

PALABRAS CLAVE: Diablo/ Iconografía/ Rock/ Mass-media/ Cultura visual.

In Nomine Satanás: the image of Devil in the rock of the 80's

\section{ABSTRACT}

This article studies satanic iconography and its relations with rock music and lyrics, the bands and their supporters, recognizing its value as a rebel symbol against the political systems and properly behaved.

KEY WORDS: Devil/ Iconography/ Rock/ Mass-media/ Visual culture.

Simpatía POR EL diABLO: GÉNESIS dE UNA ESTÉticA.

Una de las primeras grabaciones que realizó el grupo británico Venom fue In league with Satan (aliado con Satán), que posteriormente fue incluido en su primer álbum Welcome to hell (Bienvenido al Infierno) de 1981. En este tema ya esta definida la idea de Satán y la maldad como elemento vertebrador de la estética del grupo y algunos elementos icnográficos, como la cabra de Mendes que tendrán una enorme influencia en la escena underground del rock más extremo del momento y en su posterior desarrollo.
Estoy aliado con Satán
Yo me crié en el Infierno
Camino por las calles de Salem
Entre los muertos vivientes
No necesito a nadie que me diga
¿Qué esta mal o que esta bien?
Bebiendo la sangre de los niños
Acecho a mi presa en la noche

* NAVAS FERNÁNDEZ, Alexis: "In Nomine Satanas: la imagen del diablo en el rock del los años 80", en Boletín de Arte $\mathrm{n}^{\circ}$ 32-33, Departamento de Historia del Arte, Universidad de Málaga, 2011-2012, págs. 513-527. Fecha de recepción: Julio de 2011. 
Mira, ten cuidado

Cuando la luna llena alta y brillante

En todos lados estoy allí

En cada sombra, en la noche

Porque soy el mal aliado con Satán

El mal aliado con Satán

Estoy aliado con Satán

Obedeciendo sus órdenes

Con la cabra de Mendes

Sentado en su mano izquierda

Estoy aliado con Satán

Amo la muerte

Nadie rezó por Sodoma

Como la gente ha escapado

Mira, ten cuidado

Cuando la luna llena alta y brillante

En todos lados estoy allí

En cada sombra, en la noche

Porque soy el mal aliado con Satán

El mal aliado con Satán

Estoy aliado con Satán

Soy los propios amos

Bebiendo el jugo de las mujeres

Como ellos mienten solos

Estoy aliado con Satán

Llevo la marca del demonio

Matando al nuevo recién nacido

Rasgando la carne de los infantes

Mira, ten cuidado

Cuando la luna llena alta y brillante

En todos lados estoy allí

En cada sombra, en la noche

Porque soy el mal aliado con Satán

El mal aliado con Satán 
Esta fascinación por la figura del ángel caído dentro de la cultura occidental viene determinada por su fuerte presencia dentro del cristianismo. La figura del diablo dentro del cristianismo ha tenido un desarrollo más extenso que en otras religiones, este hecho viene refrendado por el número de veces que se le cita en los evangelios; aunque no siempre tenga el mismo significado ${ }^{1}$. El desarrollo de la imagen del diablo dentro de la cultura occidental ha oscilado desde un principio negativo con la fealdad más absoluta y negación de toda creatividad y poder vital como se retrata a Lucifer en el Infierno de Dante hasta la belleza del rebelde que lucha contra la opresión que toman los románticos a partir del poema de Milton El paraíso perdido (1667) ${ }^{2}$. A esto le tenemos que añadir el carácter dionisiaco (violencia y sexualidad) que tiene la figura del diablo en muchas de sus representaciones plásticas, sobre todo en Lucha de San Jorge y el dragón ${ }^{3}$. Si unimos todo esto al carácter del rock como lo define Tom Warrior (Celtic Frost)"Siempre he entendido el rock como una forma de revolución de los jóvenes contra la clase dominante"4. Atendiendo a todo esto solo era cuestión de tiempo que apareciese el black metal ${ }^{5}$.

Suele considerarse la primera manifestación del satanismo contemporáneo la película La semilla del diablo (Rosemary's Baby) de Roman Polanski, donde cuenta como una joven esposa es poseída por Satán y da a luz al diablo; además el hombre que anuncia el nacimiento del hijo del diablo es Antón La Vey el fundador de la Iglesia de Satanás ${ }^{6}$. Este satanista va a utilizar como emblema la cabra de Mendes como emblema de su grupo religioso, como podemos ver en su web www.chruchofsatan.com y que será utilizada como portada del debut de Venom y que analizaremos más adelante.

También en ese mismo año, 1968, salía a la luz la canción de los Rolling Stones Symphaty for the Devil (simpatía por el diablo) abría el disco Beggars Banquet (el banquete de mendigos). La letra de la canción esta en primera persona, lo que hace que Mick Jagger adopte el papel de un Lucifer en apariencia educado y correcto que va relatando las infamias que ha cometido en el transcurso de la historia de la humanidad ${ }^{7}$.

En ese mismo año tiene lugar la formación de Led Zeppelín y Deep Purple dos años después Black Sabbath. En esta época las estrellas de cine se incorporaban a la iglesia de Satán y como estaba de moda, las tres bandas incorporaban a su repertorio elementos de brujería: Jimmy Page (guitarrista de Led Zeppelín) estaba fascinado por la figura del ocultista Aleister Crowley y Richtie Blackmore (guitarrista

1 O'GRADY, J.: El príncipe de las tinieblas. El demonio en la historia, en la religión y en la psique humana, Madrid, Edaf, 1990, pág. 27.

2 O'GRADY, J.: Ibidem pág. 153.

3 NAVARRO, A.J.: El héroe vs el monstruo. La lucha de lo apolíneo contra lo dionisiaco en NAVARRO, A.J. y

SALA, A. (ed.) Europa imaginaria, Madrid, 200, pag.133.

4 CHRISTE, I.: El sonido de la bestia. La historia del heavy metal, Barcelona, Manontropo, 2005, pág 36.

5 Subgénero dentro del heavy metal donde predominan los temas relacionados con el satanismo y el

ocultismo. Para tener una descripción más detallada ver: http://es.wikipedia.org/wiki/Black_metal

6 RISCO,V.: Satanás, historia del diablo, Vigo, Nigratea, 2003 págs 12 y 13.

7 http://es.wikipedia.org/wiki/Sympathy_for_the_Devil 
de Deep Purple) solía llevar un puntiagudo sombrero negro de brujo ${ }^{8}$. Este gusto por el lado oscuro también lo podemos ver en el espectáculo que desarrolla en directo Alice Cooper con el titulo de Welcome to my nightmare (Bienvenido a mi pesadilla) en el que, de manera ficticia, se decapitaba.

También podemos observar un aprecio por figuras del paganismo que el cristianismo se había encargado de demonizar. El mismo año de la formación de Black Sabbath (1970) sale a la luz el segundo álbum de Santana, Abraxas portada para la que se utiliza lo obra de Matias Klarwein Anunciación (1961). Aunque podríamos ver la obra de Klarwein como una anunciación del todo irreverente al colocarle Santana el titulo de Abraxas cambia el sentido de la obra al impregnarla de paganismo. Según Leisegang, Abraxas se identifica con Mitra y por lo tanto es el mediador entre la humanidad y el dios único, el Sol invencible, culto desarrollado en los siglos III y IV9. Esta figura del mediador, con un color rojo intenso y azul en sus alas vienen a marcar más su carácter como símbolo de la santificación o espíritu santo ${ }^{10}$.

Volviendo a Black Sabbath, para muchos fundadores del genero del heavy metal, al utilizar como base rítmica de sus canciones lo que en la Edad Media se denominaba el sonido del diablo o de la bestia, la $5^{a}$ nota disminuida, el tritón ${ }^{11}$. A este hecho le tenemos que unir el interés que tenia Gezer Butler, bajista del grupo, por el ocultismo. Tenia su apartamento completamente pintado de negro, Ozzy Osburne (vocalista) le trae un libro en latín del siglo XV de magia negra, lo cual le debió producir una fuerte impresión, ya que esa noche tuvo una visión a los pies de la cama, que posteriormente dio lugar a letra del tema que da nombre al grupo ${ }^{12}$. Esta canción relata la crisis del día del juicio final: ¿qué esto que se presenta ante mí?/una figura de negro que me señala.... ${ }^{13}$.

En el primer trabajo de Black Sabbath representa una casa de campo inglesa desvencijada con la imagen de una pálida hechicera, recuerda filmes ingleses de terror psicológico y bajo presupuesto ${ }^{14}$. En el interior nos encontramos un poema inscrito en una cruz invertida, que fue impuesto por la compañía discográfica como elemento de marketing y que tendría una amplia difusión como símbolo de muchos grupos, como veremos más adelante.

En la portada del álbum más conocido de Meat Loaf, Bat Out of hell [1] (El murciélago fuera del infierno ) (1977). La escena desarrollada en un cementerio con una atmósfera onírica, crepuscular, con un cielo rojizo/anaranjado que nos traslada a un paisaje de pesadilla enfatizado con una excesiva curvatura de la tierra. Los

8 CHRISTE, I.: Op cit., pág. 26.

9 CIRLOT, J.E.: Diccionario de símbolos, Barcelona, Labor,1994, pág. 50.

10 PORTAL, F.: El simbolismo de los colores, Palma de Mallorca,Olañeta 2000, pág. 47.

11 Metal a Headbanger Journey (2005) documental.

12 Heavy la historia del metal documental.

13 CHRISTE, I.: Op cit., pág. 18.

14 Ibídem. pág 20. 
dos personajes que aparecen, un descomunal murciélago con sus alas coriáceas extendidas sobre una cripta y el motorista que surge de la tierra. Aunque la figura del murciélago puede tener significados contradictorios $^{15}$, dentro de la cultura occidental ha tenido en su mayor parte un significado negativo. Su uso en este contexto haría referencia a la muerte y el alma $^{16}$, ya que si atendemos a la letra de la canción se trata de un murciélago que escapa del infierno por la noche. Así, ambas representación harían referencia a una misma naturaleza, una naturaleza monstruosa (dionisiaca)

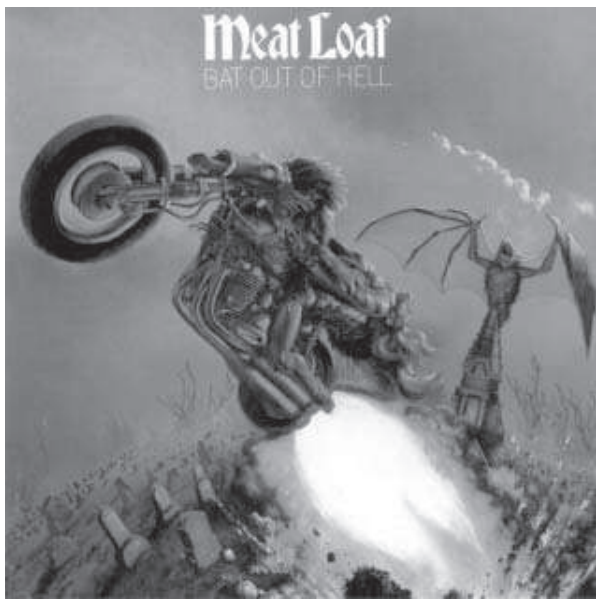

1. Meat Loaf. Bat out of hell (1977). que se enfrenta a las leyes de la razón y la proporción (apolíneo).

\section{El Príncipe de las tinieblas esta entre nosotros.}

Esta estética de principios dionisiacos, entendida como desencadenamiento de los deseos de la liberación de cualquier inhibición o represión ${ }^{17}$, dara lugar a una amplia gama de expresiones dentro de los subgénero que forman el heavy metal, como glam utilizando maquillaje y ropa femenina. Lo dionisiaco, como lo proteico, esta formado por criaturas de naturaleza ctónica, es decir, "pertenecientes a la tierra" en oposición a los héroes y los dioses del cielo ${ }^{18}$. De todas ellas se va a tomar la figura del macho cabrio identificada como imagen del diablo. En el Nuevo Testamento aparece ya identificada esta imagen con los infieles, que estaría en oposición a la imagen del cordero inmaculado que quita el pecado del mundo. A esto le podemos unir la identificación que se hace en los primeros siglos del cristianismo de las deidades paganas con seres del inframundo. Así, la figura mitológica de Pan, como símbolo de la naturaleza, suele representarse con cuernos para expresar la fuerza agresiva de Aries y los rayos del sol y el vello que cubre sus piernas expresa la vitalidad de lo inferior, las plantas, la tierra y los instintos ${ }^{19}$.

15 CIRLOT, J.E.: Op. cit., pág. 316.

16 COHEN, D.: (1989). Encyclopedia of Monsters: Bigfoot, Chinese Wildman, Nessie, Sea Ape, Werewolf and many more... Londres: Michael O'Mara Books Ltd.en http://es.wikipedia.org/wiki/Chiroptera\#cite note-152

17 CIRLOT, J.E.: Op cit. pág. 172.

18 NAVARRO, A.J.: Op. Cit. pag. 115.

19 CIRLOT, J.E.: Op. cit., pág. 354. 


\begin{tabular}{|c|c|}
\hline 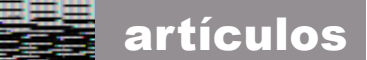 & Alexis Navas Fernández \\
\hline
\end{tabular}

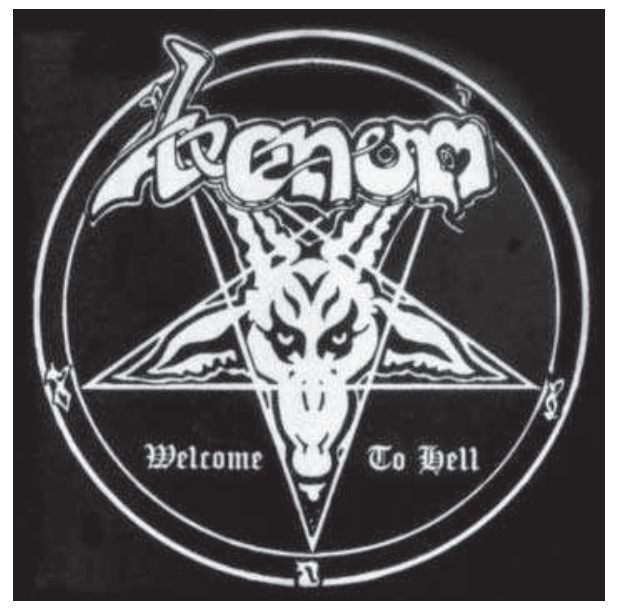

2. Venom Welcome to hell (1981).

De esta forma el acompañante de Dionisos en sus orgías alcohólicas y sexuales queda identificado con la figura del príncipe de las tinieblas.

El símbolo más universal del heavy metal son los cuernos del diablo inventado por Ronnie James Dio, de ascendencia italiana en su infancia le quedo grabada la imagen de su abuela haciendo los cuernos del diablo "malocchio" (mal de ojo) como una protección para el mal de ojo o para echarle a alguien el mal de ojo ${ }^{20}$.

El gusto por el ocultismo de la década anterior se va a prolongar durante los ochenta como podemos ver en los grupos británicos Angel Witch y Venom. Los primeros llamaran a su single de debut Baphomet, la presunta deidad adorada por los templarios ${ }^{21}$, y tomaron su imagen de Dogme et Rituel de la Haute Magie, 1854 del ocultista Eliphas Lévi. Venom también se apropio de otra imagen, el emblema de la autodenominada Iglesia de Satán, el sello de Bafomet y que utilizaría como portada de su primer álbum de 1981 Welcome to hell (Bienbenido al infierno) [2]. El uso del pentagrama o estrella de cinco puntas sobre todo en su forma invertida va ha tener una amplia difusión. En su relación con la figura humana es un símbolo ampliamente conocido que hace referencia al equilibrio ${ }^{22}$. Pero el sentido con el que la mayor parte de los grupos lo van ha adoptar es como símbolo de misterio y magia o como inversión de los valores cristianos como lo interpreta Antón LaVey al fundar su Iglesia de Satán ${ }^{23}$.

Sin necesidad de un pentagrama que lo enmarque, no menos inquietante es la imagen del álbum de debut de los escandinavos Bathory (1984), titulado con el mismo nombre del grupo, que representa la figura del macho cabrio sobre un fondo negro.

La imagen hibrida del dios Pan va ha sufrir una acentuación de su carácter animal al transformar su rostro por el del macho cabrio. Así lo podemos ver en la portada del álbum de Slayer Show no mercy (Sin piedad) de 1983 y en la carátula

20 Metal, a Headbanger Journey (2005) documental.

21 PANCORBO,L.:.Abecedario de antropologías, Madrid, España Editores, 2010. pag. 65

22 CIRLOT, J.E.: Op. Cit. pág. 380.

23 Para ver de forma más detallada la interpretación y justificación que hacen de este símbolo ver www. churchofsatan.com 


理警 artículos $\quad$ In Nomine Satanas: la imagen del diablo en el rock...

de 1987 de Bathory Under the sign of the black mark (Bajo el signo de la marca negra). De esta forma se acentúa su naturaleza ctónica. En ambas imágenes el carácter inquietantes y amenazador esta subrayado por la mirada que nos interpela, además en la primera de ellas el fuego nos sugiere el anhelo de destruir el tiempo y llevarlo todo a su final ${ }^{24}$, además la espada denota su carácter indómito de libertad y de fuerza ${ }^{25}$.

Una de las imágenes que ha tenido una difusión más amplia es la portada del álbum de 1982 The number of the beast [3] (El número

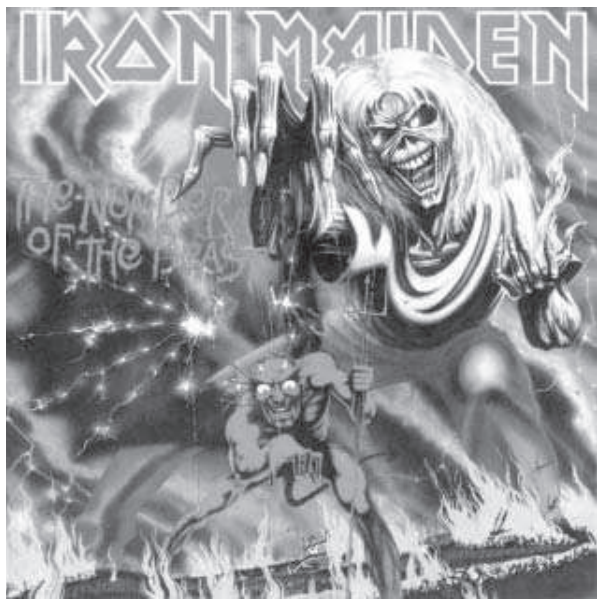

3. Iron Maiden. The number of the beast (1982). de la bestia) de Iron Maiden. En un infierno superpoblado, que apenas podemos ver a los condenados, por su pequeño tamaño, aparecen algunas diminutas figuras de diablos revoloteando, como en la visión del monje Fursa, recogida por Beda a principios del siglo VIII que contempla el infierno con una muchedumbre de diablos volando y aumentando los fuegos ${ }^{26}$. La figura central es el alter ego del grupo "Eddy" que maneja como una marioneta al diablo en el infierno, imagen que nos hace pensar que no hay causa consecuencia pues todo esta determinado, negando de esta forma la libertad del hombre. La figura del diablo esta adornada con uno de sus atributos más característicos: el tridente. Este es también atributo del dios del inconsciente y de la culpa como Neptuno y según Bayley se trata de una cruz alterada para darle agresividad ${ }^{27}$. No hay que olvidad que el color rojo intenso que esta asociado al diablo como fuego del infierno era también el color con el que se identificaba a la antigua deidad pagana de Pan y Dionisio ${ }^{28}$.

La que podríamos denominar como probablemente la portada más cristiana del rock de los ochenta, arroja al diablo al infierno. Stryper, To hell with the Devil (al infierno con el Diablo) 1986. Pero al parecer no tuvo la recepción esperada por parte del grupo: "Recibimos un montón de críticas por parte de personas cristianas que pensaron que habíamos puesto una estrella de cinco puntas (...). Uno de los ángeles

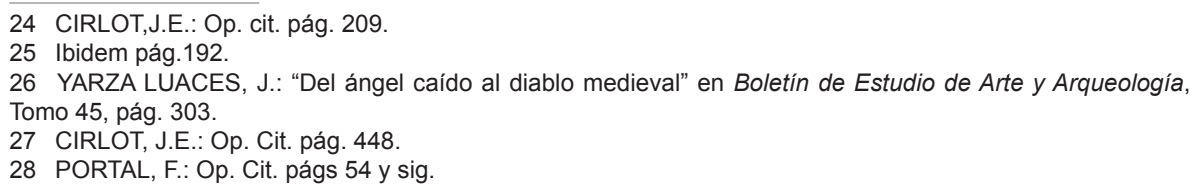




\begin{tabular}{|c|c|}
\hline 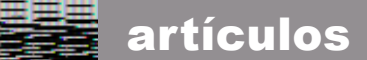 & Alexis Navas Fernández \\
\hline
\end{tabular}

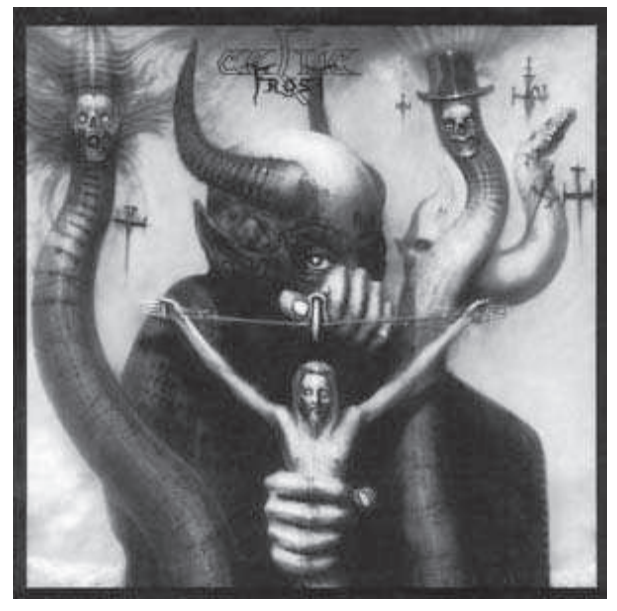

4. Celtic Frost. To Mega Therion (1986). le había arrancado un collar a Satán y lo había arrojado por el aire, y ésa es la estrella de cinco puntas"29.

Una visión distinta del Diablo es la que nos ofrecen Celtic Frost To Mega Therion [4] (la gran bestia ) (1986). El pintor suizo $\mathrm{H}$. R. Giger permitió que usaran gratis un cuadro suyo de 1977 titulado Satan $I$, en el que se ve a un demonio con tentáculos armado con una honda fabricada con los brazos estirados de un Cristo crucificado $^{30}$. Más que demonios convencionales el personaje aquí utilizado parece uno de los seres primordiales, llenos de tentáculos, que pueblan los relatos de $\mathrm{H}$. P.

Lovecraft, que no sabemos bien si ha atrapado a Cristo en su descenso a predicar en el infierno o ha asalto el cielo hasta hacerse con el poder total.

\section{DIOS NOS ODIA A TODOS: LA CRUZ INVERTIDA Y LA CRUCIFIXIÓN.}

En el primer trabajo de Black Sabbath (1970) aparece en el interior una cruz invertida con un poema inscrito en el interior. Este símbolo va ha tener una amplia profusión dentro de los grupos que forman lo que la critica música ha denominado como primer black metal; así lo podemos ver en la portada del álbum de Venom, At war with Satan (en guerra con Satanás) (1983) en el maquillaje que utiliza King Diamond, vocalista de Mercyful Fate en la portada de Black Funeral (funeral negro) [5] (1983), y en las fotos promociónales de grupos como Slayer, Bathory o Celtic Frost. También, lo podemos ver en la portada del primer trabajo de los norteamericanos Possessed titulado Seven Churches (Siete Iglesias) (1985). Invirtiendo la posición de la cruz, símbolo cristiano de adoración a Cristo, se convierte en un símbolo en un símbolo de adoración a su antagonista: el diablo.

El álbum de Venom que hemos citado cuenta la saga completa del ataque al paraíso por parte de los demonios expulsando a los ángeles y estos se reorganizan en

29 CHRISTE, I.: Op cit., págs 127 y 128.

30 Ibídem. pág. 118. 
el infierno regresan para destruir la fiesta demoníaca de la victoria ${ }^{31}$. Este relato hunde sus raíces en la creencia medieval desarrollada en los siglos XIV y XV de que los ángeles caídos, junto con sus adoradores en la tierra volverían al cielo y echarían al arcángel San Miguel y a sus ángeles, quienes tomarían su puesto en el infierno ${ }^{32}$.

La lealtad nominal que estos grupos profesaban al diablo funcionaba como señal contra la aceptación del público en general; se trataba de aplastar las restricciones sociales y generar un espacio para la diversión sin trabas. En palabras de

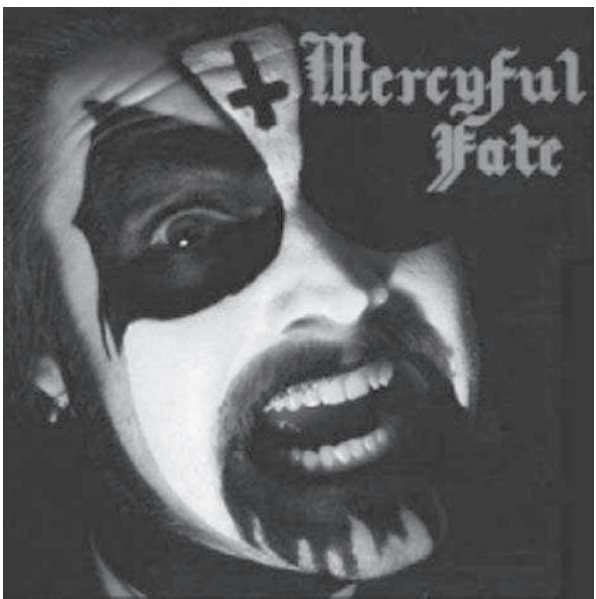

5. Mercyful Fate. Black Funeral (1983). Larry Lalonde (Possessed) " $\mathrm{i}$ Si crees en toda esa historia de Satán, es que eres estúpido!"33 Esta oposición a las doctrinas del cristianismo estaría motivada por el rechazo a la formación religiosa de muchos de los componentes de las bandas de heavy metal como Ronnie James $\mathrm{Dio}^{34}$. Los aspectos satánicos del rock asustaban en Norteamérica en especial en el denominado cinturón de la Biblia (zona centro y sur de Estados Unidos caracterizados por un fuerte puritanismo) ${ }^{35}$.

Por todo esto no es de extrañar la voluntad de invertir, aunque sea en un plano simbólico, los valores del cristianismo. Si la imagen de Cristo en la cruz constituye el emblema por excelencia del cristianismo ahora se trata de darle la vuelta.

Este espíritu es el que se desprende de la portada del primer trabajo de los brasileños Sepultura de 1986, Morbid Visions [6] (Visiones morbosas). Aunque podemos encontrar la figura del diablo en la crucifixión como en la obra de Bramantino de 1515, [7] el instante que esta aquí reflejado es el posterior a la muerte de Cristo en Mateo 27,52 la tierra tembló, las rocas se rajaron. Y la plegaria que Lucas 23, 46 Padre, a tus manos encomiendo mi espíritu, parece que solo la ha escuchado el demonio que sale de las profundidades del infierno para apoderarse de la figura de Cristo.

Con un carácter mas irreverente podemos ver la portada del EP de 1982 de

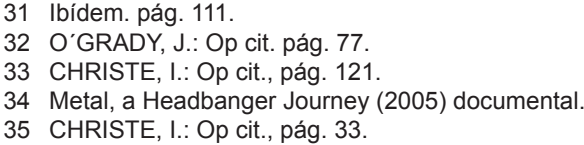




\begin{tabular}{|c|c|}
\hline 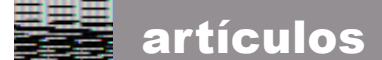 & Alexis Navas Fernández \\
\hline
\end{tabular}

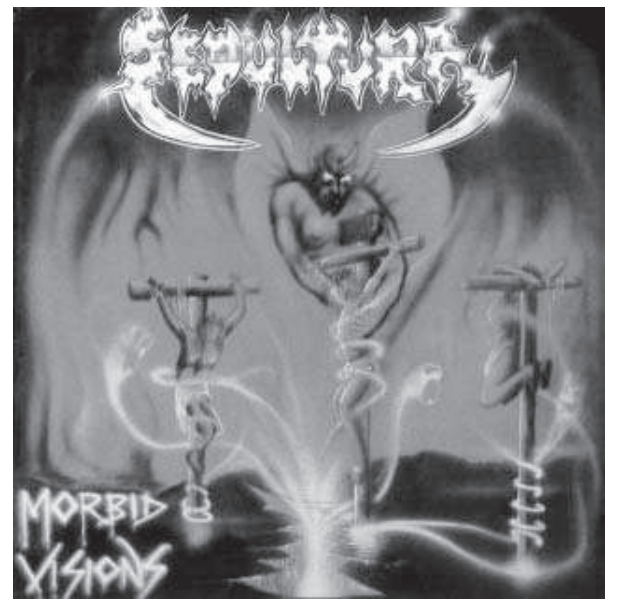

6. Sepultura. Morbid Visions (1986).

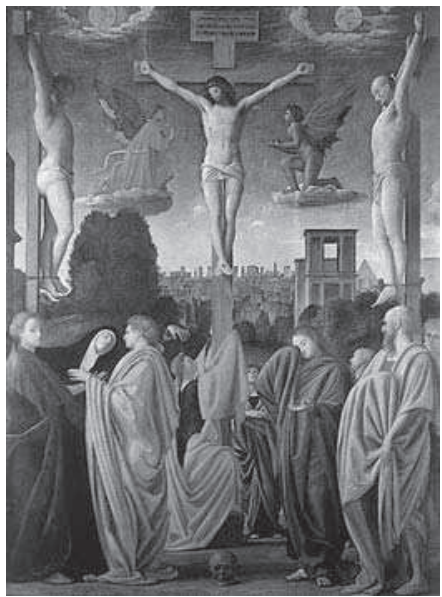

7. Crucifixión, Bramantino (1515).

Mercyful Fate Nuns have no fun (Las monjas no tienen diversión). Una escena que por su titulo bien podría estar sacada de la novela gótica y decadentista del siglo XIX. Las figuras de los monjes alrededor de una cruz con una mujer voluptuosa desnuda sobre ella parecen estar a medio camino entre la imagen del frailes duende de Los Caprichos (1799)de Goya y Ambrosio, el protagonista de la novela El monje (1795) de Lewis.

Junto con la cruz invertida también aparecen en las imágenes promociónales de estos grupos junto con calaveras haciendo un uso tradicional de este emblema de la caducidad de la existencia. Pero también aparece como vaso de la vida y del pensamiento que es como aparece en los libros de alquimia en relación con el nigredo (designa la primera de tres fases, en la transmutación de la materia. Asociada a la putrefacción, involucra una disolución en la materia prima, para la generación de otra superior $\left.{ }^{36}\right)$. Gran número de actos y rituales derivan de este sentido ${ }^{37}$.

En otras imágenes promociónales en las que se retratan junto a calavera, aparecen blandiendo armas como si se tratase de diablos recién nacidos, como el caso de Venom ${ }^{38}$. Esta imagen de púas y cuero la toman de Judas Priest ${ }^{39}$, aunque estos grupos le dan una vuelta de tuerca llevándola, con toda suerte de imaginaria satánica.

39 Ibídem. pág. 83. 
EL INFIERNo ESPERA: DONDE EL GUSANO NO MUERE Y EL FUEGo NO SE APAGA.

En las profundidades de mi hogar de fuego

Repicara la campana

Las primeras nociones que nos han llegado del infierno están despojadas de cualquier idea de castigo o gratificación ${ }^{40}$. Podemos decir que la idea de infierno en términos generales alude a una forma de subvida, la vida lastrada de los muertos en el interior de la tierra ${ }^{41}$.El infierno ha sido, y es en la actualidad entendido de muchas maneras distintas. La palabra hebrea Seol, al igual que el Hades de los griegos definía de forma neutra como la morada de los espíritus de los difuntos. Posteriormente, tras el exilio a Babilonia y en la época de los Evangelios Apócrifos, el lugar de castigo se convirtió en Gehena, el tormento de azufre y fuego para los impíos ${ }^{42}$. En Mateo 23:33 Jesús dice: "Vosotros, serpientes, generación de víboras, ¿cómo podréis escapar al castigo del Gehena?" Esta palabra se encuentra también en la Epístola de Santiago. Muchos cristianos asimilan gehena como el lugar de castigo eterno llamado infierno ${ }^{43}$. En otras citas de la Biblia el infierno se encuentra situado en las profundidades de la tierra y orientado al norte. En Isaías 14:13 "Y tú decías en tu corazón: Subiré a los cielos; en lo alto, sobre las estrellas del cielo, elevaré mi trono, y me asentaré en el monte de la asamblea, en las profundidades del aquilón". El norte se relaciona con el frío y la falta de luz, además de situarse en el lado siniestro si se entra en una iglesia por el oeste. Era un lugar poco recomendado y la gente prefería no enterrarse en este lado del templo ${ }^{44}$.

En los primeros siglos de nuestra era tanto en el cristianismo como en otras creencias se produce un auge de las creencias infernales como castigo ${ }^{45}$. Las creencias en los penas del infierno, el fuego eterno entre otras, se van consolidando en los primeros siglos del cristianismo dando lugar a la creencia en el castigo eterno ${ }^{46}$

A esto le tenemos que añadir la enorme influencia que tuvo la cábala judía en la iglesia cristiana de la Edad Media sobre la idea de infierno al asociarlo a la materia y al dividirlo en departamentos correspondientes a cada pecado ${ }^{47}$. La profusión de imágenes del infierno lo podemos achacar a que en una época en que el analfabetismo era la norma general era una forma de recordarles que deben permanecer fieles a las enseñanzas de la iglesia para no sufrir los tormentos del infierno.

40 MINOIS, G.: Historia de los infiernos, Paidós, Barcelona, 2005, pág. 20

41 CIRLOT,J.E.: Op. Cit. Pág. 251.

42 O'GRADY, J.: Op. Cit. pág. 62.

43 METZGER \& COOGRAN.: Oxford Companion to the Bible, Oxford, 1993, pág. 243. en http://es.wikipedia.org/wiki/Gehena

44 ARAGONES, E.: Mi reino no es de este mundo en http://diabloenelarte.blogspot.com.es/

45 MINOIS, G.: Op. cit, pág. 97.

46 Podemos ver este proceso de forma detallada en: Crecimiento y excrecencias de la pesadilla (siglos III-XIII) en MINOIS, G.: Op cit.

47 O'GRADY, J.: Op. Cit. pág. 62 


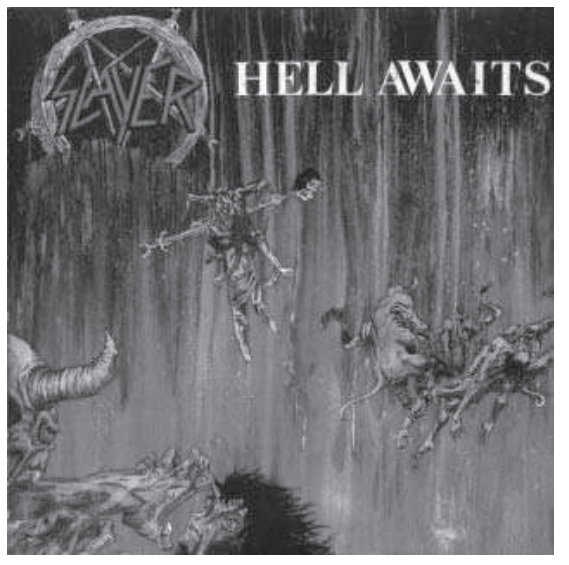

8. Slayer. Hell Awaits (1985).

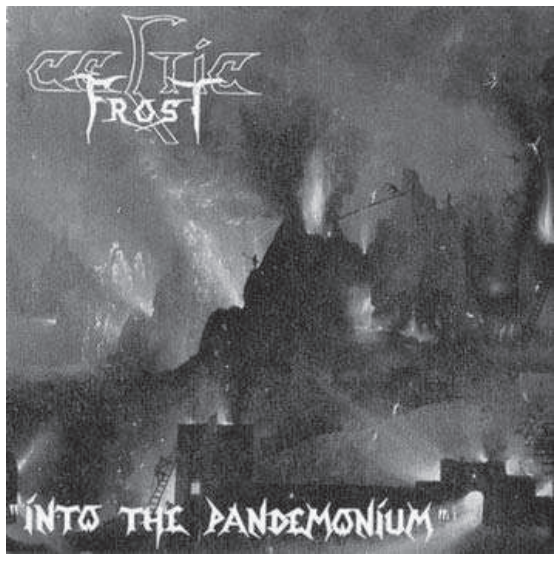

9. Celtic Frost. Into the Pandemonium (1985).

Esta imagen de un infierno de fuego y de torturas a los condenados es la que podemos encontrar en la portada del segundo álbum de Slayer de 1985, Hell Awais [8] (El infierno espera). Entre las llamas de la condenación podemos ver como en primer término un demonio se dispone a torturar a un condenado ante el rostro de desesperación de este. Mientras tanto, un grupo de tres demonios como despedazan a un condenado, y en último termino otro demonio sobre las espaldas de un condenado con una gran espada con la cabeza de un decapitado. El fuego que aquí aparece nos remite al fuego de la condena como lo describe Lactancio a principios del siglo IV “...es puro, quema sin humo, fluye como el agua, no se eleva, se nutre de los condenados al mismo tiempo que los reconstituye"48

También presidía por el fuego del infierno es la imagen que utiliza banda suiza Celtic Frost para su álbum Into the Pandemonium, [9] también de ese mismo año. Toma el titulo de la capital del infierno en el poema de Milton Utilización de un fragmento de la obra de Jeronimó Bosco, El Jardín de las delicias concretamente del panel derecho que representa al infierno. Se ha utilizado un fragmento de la arquitectura en llamas, si atendemos a la idea que los paneles laterales son una inversión uno del otro, esta imagen se contrapone con las montañas "naturales" del paraíso ${ }^{49}$. Los incendios de estructuras son una constante en la obra del Bosco como podemos ver en El carro del heno y en el tríptico del Juicio de Viena; el fuego viene de abajo como inspirándose en las armas de pólvora o explosivos, con lo cual sus infiernos acaban pareciendo lugares de confrontación militar ${ }^{50}$. Además, si atendemos a la interpretación de Gibson la representación del infierno en el Carro de Heno, el Averno se construye ladrillo a ladrillo con los pecados de los hombres.

48 LACTANCIO, Institud, divin., VII, XXI. En MINOIS, G.: Op. cit, pág. 138.

49 RAMIREZ, J.A.: El Bosco, Madrid, 2005, Unidad Editorial, pág. 17 en ARAGONES, E.: La muerte en el Infierno: A propósito del hombre árbol del Jardín de las delicias del Bosco, De Arte, n6, 2007, pág. 132.

50 RAMIREZ, J.A. Op. Cit en http://es.wikipedia.org/wiki/Tr\%C3\%ADptico_del_Juicio_de_Viena 


\begin{tabular}{|c|c|c|}
\hline 非非 & articulos & In Nomine Satanas: la imagen del diablo en el rock... \\
\hline
\end{tabular}

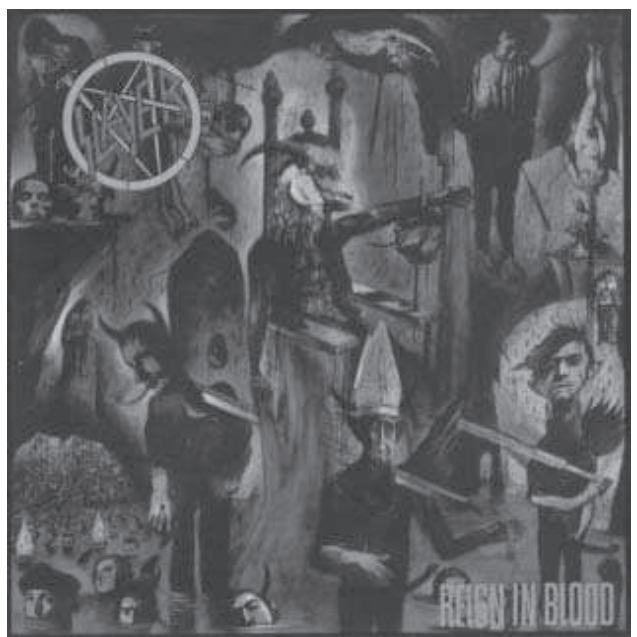

10. Slayer. Reign in blood (1986).

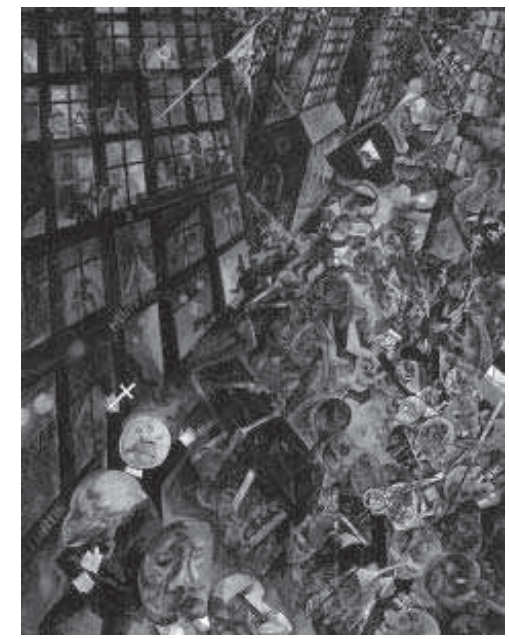

11. Exequias, Otto Dix (1917 - 1918).

Ante estas imágenes en las que apenas podemos ver condenados en el infierno, contrasta con la del siguiente trabajo de Slayer de 1986, Reign in Blood [10] (Reino de sangre) en la que aparece un infierno superpoblado en el que tiene lugar la entronización de la figura del diablo, asimilado al macho cabrio; y que sería una clara burla a la entronización de la figura papal. Este infierno parece que responde a la máxima fuera de la Iglesia no hay salvación. Esta opinión de que el infierno esta repleto la podemos encontrar a fines de la Edad Media y también en los siglos XVI y XVII51. En este infierno superpoblado podemos identificar distintos personajes entre los condenados: por un lado están los que ya han sufrido las penas del infierno: degollados, empalados...., además entre los múltiples condenados en el infierno podemos identificar personajes pertenecientes a la jerarquía de la iglesia al estar tocados con la mitra. Gran parte de los condenados se encuentran cubierto por un lago de aguas rojas que podríamos encontrar en las primeras descripciones que se hace del infierno cristiano. En el Apocalipsis de Pedro, escrito entre el 125 y 150, esboza una clasificación de las penas del infierno según el tipo de pecado: "Había allí un gran lago lleno de fango ardiente, donde se hallaban algunos hombres que se habían apartado de la justicia"52.

Las portadas de sus álbumes posteriores van a seguir la misma tonalidad oscura y crepuscular que en cierto modo nos recuerda el tono apocalíptico y desgarrador, sin ningún atisbo de piedad ni misericordia de algunas pinturas de Otto Dix como Exequias, dedicado al poeta y medico Oscar Panizza (1917-18) [11] pero con una composición marcada por

51 MINOIS, G.: Op. cit, págs 331 y sig.

52 Ibídem pág. 105 


\begin{tabular}{|c|c|}
\hline 理 & Alexis Navas Fernández \\
\hline
\end{tabular}

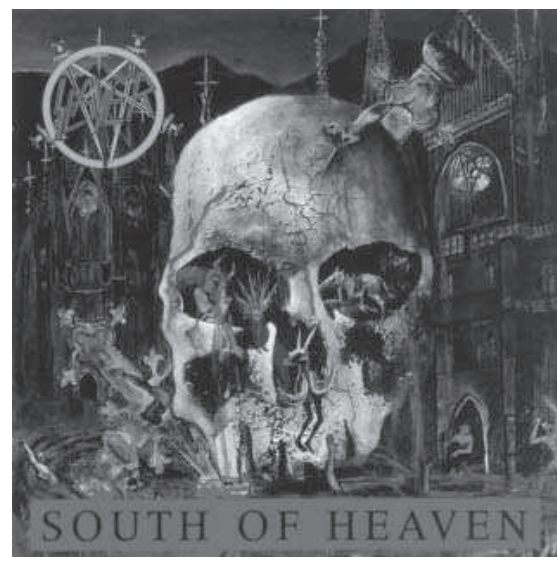

12. Slayer. South of Heaven (1988).

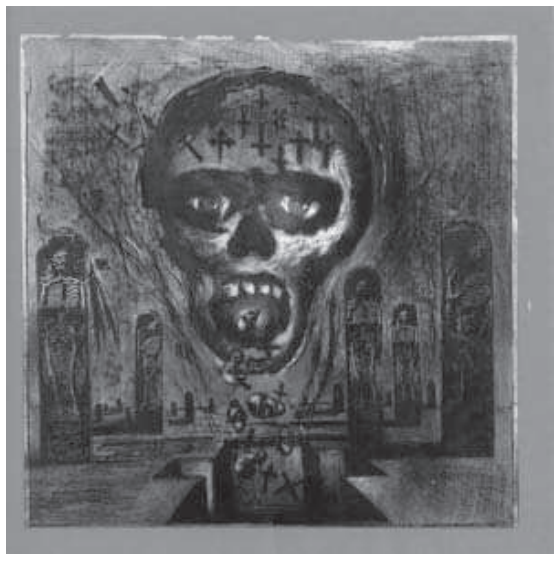

13. Slayer. Seasons in the Abyss (1990).

la planitud. En su siguiente trabajo de 1988 South of Heaven [12] (Al sur del cielo) una enorme calavera, símbolo de la futilidad de la vida, preside la escena. Rememorando el tema tan ampliamente tratado de la muerte en el infierno por la pintura flamenca. Poblada esta por animales y seres zoomorfos, la escena se encuentra enmarcada por sendas iglesias góticas. Los condenados han desaparecido de la escena engullidos por un torrente de sangre, un remolino que bien nos puede recordar la potencia con el Maelstrom engulle a barcos y personas en el relato de Edgar Allan Poe Un descenso al Maeltrom.

Siguiendo la línea de trabajos anteriores, pero alejado de tanto artificio escénico, su siguiente trabajo de 1990 Seasons in the Abyss [13] (Temporadas en el abismo) La escena se desarrolla en lo que podríamos identificar como un fantasmal cementerio, donde podemos incluso ver los esqueletos de los difuntos en sus nichos y como una gran cabeza va vertiendo cabezas y cruces en una hendidura en forma de cruz en la tierra. Esta hendidura bien podría ser una de las puertas del infierno o el mismísimo seol de los hebreos que en distintos textos que en distintos textos del Antiguo Testamento se identifica como una inmensa cavidad ${ }^{53}$.

Mucho más sugerente en su invocación al inframundo es la portada del segundo álbum de Bathory en 1985, The Return (El regreso), en la que podemos ver un retrato de la luna ocultándose detrás de las nubes. Se trata de una imagen más o menos neutra que empleada por parte de uno de los primeros grupos de black metal toma una connotación siniestra al sugerirnos la visión del infierno en forma de ausencia. Esta imagen funciona de igual manera que el Nacimiento de Venus de Botticelli que a través del velo de la belleza

53 Ibidem pág. 28. 
de Venus nos remite a la ausencia inquietante de su padre Urano ${ }^{54}$.

Posesiones y nUeVos nacimientos: LA INFANCIA SATÁNICA.

Si en el epígrafe anterior hablábamos de un lugar común del terror popular, el infierno, ahora viraremos hacía un territorio donde muchas mentes no esperan encontrarse con ningún tipo de inquietud ni sobresalto: la infancia.

El pequeño infante que habita el infierno parece ser el protagonista de la portada del álbum de Black Sabbat Born Again [14] (Nacer de nuevo) de 1983. Esta imagen que nos puede evocar las serigrafías de Andy Warhol, nos muestra un pequeño diablo coloreado con un rojo intenso, con garras incipientes, dientes de vampiro y con la frente coronada por dos pequeños cuernos. Este pequeño habitante del infierno guarda fuertes similitudes corporales con el bebe caníbal dotado de garras y largos colmillos del film Estoy vivo de 1974. Ambos personajes bien podrían ser los niños que habitan el infierno descrito en el Apocalipsis de Pedro : "Frente a ellas yacía un gran número de niños nacidos antes de término que gritaban. De estos partían chorros de llama que daban a las mujeres en los ojos. Eran las que habían concebido fuera del matrimonio y habían matado a sus hijos" ${ }^{\prime 5}$. Otra representación de la figura de los bebes demonio, menos inquietante que las anteriores, la podemos encontrar en la Iglesia de San Lesmes de Burgos, en un retablo de la escuela castellana del siglo XVI.

Una infancia en apariencia mucho más tranquila y bien intencionada es la que ilustra el álbum Possessed (Poseídos) de 1985 de Venom. La imagen de dos niños se nos muestra en un negativo fotográfico para poner de manifiesto el carácter sobrenatural de la posesión. En los Evangelios se le da credibilidad al tema de las posesiones diabólicas, en el siglo III se crea el ministerio de exorcista y en 1614 el Papa Pablo V publica el Ritual Romano, todavía hoy utilizado, que se utiliza en las ceremonias y métodos del exorcismo; en el se especifica que los niños no pueden estar presentes en un exorcismo extraordinario porque al salir el demonio de un cuerpo podría entrar en el suyo al estar indefensos ${ }^{56}$. Que es lo que parece que les ha ocurrido a los protagonistas de esta imagen.

54 TRIAS,E.: Lo bello y lo siniestro, Barcelona, Ariel, 1992 pág. 72.

55 MINOIS, G.: Op. cit, pág. 106.

56 O’GRADY, J.: Op. Cit. pág.147. 
